\title{
Inactivation of Listeria innocua on Frankfurters by Flash Pasteurization and Lauric Arginate Ester
}

\author{
Christopher Sommers ${ }^{1 *}$, William Mackay ${ }^{2}$, David Geveke ${ }^{1}$, Bryan Lemmenes ${ }^{3}$ and Seth Pulsfus ${ }^{3}$
}

${ }^{1}$ Eastern Regional Research Center, U.S. Department of Agriculture, Agricultural Research Service, Wyndmoor, Pennsylvania, USA ${ }^{2}$ Edinboro University of Pennsylvania, Pennsylvania, USA

${ }^{3}$ Alkar-RapidPak, Inc., Lodi, Wisconsin, USA

\begin{abstract}
Listeria monocytogenes, a psychrotrophic food-borne pathogen, is a recurring post-process contaminant on ready-to-eat meat (RTE) products including frankfurters. Flash Pasteurization (FP) uses short pulses of steam to decontaminate the surface of precooked sausages such as frankfurters. The antimicrobial lauric-arginate-ester (LAE) has been shown to reduce levels of $L$. monocytogenes and its nonpathogenic surrogate $L$. innocua on frankfurters. In this study the use of FP to inactivate $L$. innocua on frankfurters followed by application of LAE immediately prior to vacuum-packaging in a pilot plant setting was investigated. Use of FP $\left(1.5 \mathrm{~s}, 120^{\circ} \mathrm{C}\right.$ steam $), \operatorname{LAE}(3.33 \mathrm{ml}$ of a $5 \%$ volume/volume solution per pack of four frankfurters), or FP followed by application of LAE, resulted in a 2.5 , 1.6 , and 3.3 of log reductions of $L$. innocua that was surface-inoculated onto frankfurters, respectively. Although FP alone reduced $L$. innocua levels by $2.5 \mathrm{log}$, the bacterium recovered and grew to a density of $>10^{6} \mathrm{CFU} / \mathrm{g}$ within 2 weeks during refrigerated storage $\left(10^{\circ} \mathrm{C}\right)$. LAE inhibited $L$. innocua growth for 8 weeks, but the bacterium was able to recover and grow to a density of $>10^{6} \mathrm{CFU} / \mathrm{g}$ by week 12 . The use of FP in combination with LAE effectively inhibited the growth of $L$. innocua for 12 weeks. The use of FP in combination with LAE had little effect on frankfurter color and texture, and was found to be an effective hurdle process for decontamination of frankfurter surfaces.
\end{abstract}

\section{Introduction}

Listeria monocytogenes is an occasional post-process contaminant on ready-to-eat (RTE) meat products, including frankfurters, and while control of this pathogen has improved significantly in recent years, it is responsible for a number of food-borne illness outbreaks and product recalls [1-6]. L. monocytogenes is capable of growth at refrigerated temperatures and in high salt environments, which allows it to proliferate during long-term cold storage [7] and readily grows in refrigerated ready-to-eat meat products such as deli meats and frankfurters [8]. Control of this microorganism is important because the lower number of bacterial cells accidentally consumed, the lower the risk of contracting listeriosis, which is important due to the increasing percentage of at risk individuals such as diabetics or the elderly in the U.S. $[9,10]$. Because of the high mortality rate $(20-30 \%)$ associated with listeriosis, this pathogen is given zero tolerance in ready-to-eat meat products in the United States [11].

Frankfurters surfaces are typically contaminated by microorganisms, including L. monocytogenes, after the cooking process and prior to packaging. There are many intervention technologies that can be used to inactivate foodborne pathogens on pre-cooked sausage and ready-to-eat meat products including antimicrobials [8] high pressure processing [12], infrared light [13], in-package thermal treatments [14], ionizing radiation [15], ultraviolet light [6], pulsedlight [16], etc.

While many technologies are available to improve the microbiological safety and shelf-life of precooked sausages, those actually in commercial use are relatively few because of the need for effectiveness, low cost, and the ability to use the technology at commercial processing line speeds. Flash Pasteurization (FP), uses short pulses of steam $\left(120^{\circ} \mathrm{C}, 1.5 \mathrm{~s}\right)$ to decontaminate the surfaces of fine emulsion sausages such as frankfurters or bratwurst immediately before packaging [17]. FP inactivates 2-3 log CFU/g of L. monocytogenes and L. innocua on precooked sausage surfaces, however, the bacteria are eventually able to recover and proliferate during long-term refrigerated storage. Lauric Arginate Ester (LAE), which is metabolized into natural substances when consumed, is Generally Recognized As Safe (GRAS) by the U.S. Food and Drug Administration, and is applied to RTE meats and packaging surfaces immediately prior to vacuum-sealing. PortoFett et al. [22] found that, while LAE inactivated 1-2 log CFU/g of $L$. monocytogenes on frankfurter surfaces, the food-borne pathogen was able to recover and proliferate to approximately $7 \log \mathrm{CFU} / \mathrm{g}$ during long-term refrigerated storage at $4^{\circ} \mathrm{C}$. This outcome was improved when LAE was combined with the antimicrobials sodium diacetate (SDA) and potassium lactate (PL), a phenomenon also observed by other researchers [6].

The most effective approach to improving the microbial safety and quality of foods is the hurdle approach, which involves the combinatorial use of physical and chemical intervention technologies, to improve microbial inactivation and outgrowth during long-term storage. Physical interventions such as ultraviolet light (UV-C), in combination with heat, are more effective than UV-C or heat alone [5]. FP in combination with antimicrobials including SDA and PL mixtures or organic acids is more effective than either technology used by itself $[7,18,19]$. Sommers et al. [6] demonstrated that UV-C, when used in combination with LAE, SDA and PL was more effective for controlling

*Corresponding author: Christopher H. Sommers, Research Leader, Food Safety and Intervention Technologies Research Unit, Eastern Regional Research Center, USDA-ARS, 600 East Mermaid Lane, Wyndmoor, PA 19038, USA, Tel: 215-836-3754; Fax: 215-233-6445; E-mail: Christopher.sommers@ars.usda.gov

Received January 31, 2012; Accepted February 21, 2012; Published February 24, 2012

Citation: Sommers C, Mackay W, Geveke D, Lemmenes B, Pulsfus S (2012) Inactivation of Listeria innocua on Frankfurters by Flash Pasteurization and Lauric Arginate Ester. J Food Process Technol 3:147. doi:10.4172/2157-7110.1000147

Copyright: (C) 2012 Sommers C, et al. This is an open-access article distributed under the terms of the Creative Commons Attribution License, which permits unrestricted use, distribution, and reproduction in any medium, provided the original author and source are credited. 
L. monocytogenes, Salmonella, and Staphylococcus aureus on frankfurter surfaces than either UV-C or the antimicrobials alone. In summary, the most effective means for controlling Listeria spp. in ready-to-eat meat products is the combination of multiple intervention processes. This is the first study that investigates the use of FP in combination with LAE as a food safety intervention technology.

The purposes of this study were to: (1) determine the effect of the combinatorial use of FP and LAE to inactivate the L. monocytogenes surrogate $L$. innocua on the surface of frankfurters in a pilot plant setting; (2) to determine the growth potential of L. innocua on FP and LAE treated frankfurters during refrigerated storage $\left(10^{\circ} \mathrm{C}\right)$; and $(3)$ to determine the effect of FP and LAE on frankfurter color and shear force.

\section{Materials and Methods}

\section{Frankfurters}

Frankfurters were purchased from a local processor. The frankfurters consisted of beef, water, salt, flavoring, paprika, sodium phosphate, sodium nitrate and were $25 \%$ fat. They did not contain antimicrobials such as sodium diacetate and potassium lactate. Frankfurters were stored at $-20^{\circ} \mathrm{C}$ and thawed overnight for experimentation the following day.

L. innocua: Three L. innocua isolates $(51742,33090,33091)$ were obtained from the American Type Culture Collection (Manassas, VA, USA). The strains were propagated on Tryptic Soy Agar (BD-Difco Laboratories, Sparks, MD, USA) at $37^{\circ} \mathrm{C}$ and maintained at $0-2^{\circ} \mathrm{C}$ until ready for use. Identity of Listeria was confirmed by Gram Stain followed by analysis with Gram Positive Identification (GPI) cards using the Vitek Automicrobic System (bioMerieux Vitek, Inc., Hazelwood, MO, USA).

L. innocua propagation and inoculation: Each $L$. innocua strain was cultured independently in 30-mL Tryptic Soy Broth (Difco) in 50$\mathrm{mL}$ sterile tubes at $37^{\circ} \mathrm{C}(150 \mathrm{rpm})$ for $18 \mathrm{~h}$. The cultures were then diluted in Butterfield's Phosphate Buffer (BPB) (Applied Research Institute, Newtown, CT, USA) as a mixture. Refrigerated frankfurters were then placed on a sterile surface, rolled in $1 \mathrm{ml}$ of diluted inoculum, including the ends, to a final concentration of $10^{5} \mathrm{CFU} / \mathrm{g}$, and placed in a refrigerator for approximately 30 minutes prior to $\mathrm{FP}$ or LAE treatments. The inoculation, $10^{5} \mathrm{CFU} / \mathrm{g}$, is relatively high in comparison to the low numbers generally associated with naturally occurring contaminations of frankfurters [20]. Preliminary experiments revealed an inability to recover viable $L$. innocua following treatment at lower inoculations $\left(10^{2}-10^{3} \mathrm{CFU} / \mathrm{g}\right)$ that would typically represent the upper limit of naturally occurring contaminations [20].

\section{Flash pasteurization}

To assess the effect of the FP inactivation process, the surfaceinoculated frankfurters were loaded into open preformed trays at the inlet of the Flash Pasteurization prototype unit (Alkar-RapidPak, Lodi, WI) as a single layer of 4 frankfurters [19]. The frankfurters were then exposed to steam treatments $\left(120^{\circ} \mathrm{C}\right)$ for $1.5 \mathrm{~s}$. Following treatment, the frankfurters were placed in sterile polynylon bags (Uline, Inc., Philadelphia, PA) which were stored in an ice-water bath prior to enumeration of L. innocua.

\section{Lauric arginate ester}

Lauric Arginate Ester (Cytoguard ${ }^{\mathrm{TM}}$ ) and Cytoguard-STAT-N ${ }^{\mathrm{TM}}$ were obtained from A\&B Ingredients (Fairfield, NJ). Cytoguard-
STAT-N is a mixture of bacterial growth inhibitors made to improve the effectiveness of LAE. LAE was suspended in Cytoguard-STAT-N to a final concentration of $5 \%$. The $5 \%$ concentration and volume were based on previous research and manufacturer's recommendations for the concentration and volume. Approximately $3.3 \mathrm{ml}$ were added to four frankfurter packs in polynylon bags (Uline, Inc., Philadelphia, PA, USA) using a Badger Model industrial paint sprayer, and then vacuum sealed $(30 \mathrm{mB})$ using a Multi-Vac A300 packager (MultiVac, Inc., Kansas City, MO, USA).

\section{Flash pasteurization and Lauric arginate ester}

The same procedures were used as stated above with the exception that the LAE was added immediately following FP. The frankfurter packages were then vacuum-sealed as described above.

Recovery and plating of L. innocua: Following FP the samples were assayed for colony forming units (CFU's) by standard pour plate procedures. Fifty-mL of sterile DE Buffer (Remel, No. R453042, Lenaxa, KS, USA) was added to a polynylon bag that contained 4 frankfurters and shaken manually for $1 \mathrm{~min}$ in order to resuspend the bacteria and neutralize the LAE. Failure to neutralize the LAE solution results in an overestimation of the log reduction of microorganisms as a result of inhibition of growth of the pathogens following diluting and plating [6]. Suspension of the frankfurters in BPB, peptone water, or buffered peptone water, as opposed to DE Buffer, yielded unsatisfactory results [6]. The samples were then serially diluted in BPB, using tenfold dilutions, and $0.1-\mathrm{mL}$ of diluted sample was pour plated using Palcam Medium (BD-Difco, Inc., Sparks, MD, USA). Two 0.1-mL aliquots were plated per dilution. The Palcam plates were then incubated for approximately $72 \mathrm{~h}$ at $37^{\circ} \mathrm{C}$ prior to enumeration for CFU, as opposed to $48 \mathrm{~h}$ which is typically used for Listeria spp., to further mitigate the effect of LAE on growth rate during the incubation period. Each experiment was conducted independently three times $(n=3)$.

Storage study: The same inoculation and recovery procedures were used and described in the previous sections. Single layer packages of frankfurters were held at $10^{\circ} \mathrm{C}$ for 12 weeks. The temperature for long term storage was selected based on USDA FSIS recommendations for evaluation of post-process interventions and alternative [21] Frankfurter packs were sampled every two weeks. Each experiment was conducted independently three times $(n=3)$.

Color analysis: Color analysis was performed using a Hunter Lab Miniscan XE Meter (Hunter Laboratory, Inc., Reston, VA, USA) [19]. The meter was calibrated using white and black standard tiles. Illuminate $\mathrm{D} 65,10^{\circ}$ standard observer, and a $2.5-\mathrm{cm}$ port/viewing area were used. Results are from three independent experiments, with three readings taken per experiment.

Shear force: Cutting force of the frankfurters was measured using a Texture Technologies Corp. (Scarsdale, NY, USA) TA-XT2 Texture Analyzer. A TA-7 Warner-Bratzler Blade was used with a test speed of $2.0 \mathrm{~mm} / \mathrm{s}, 55 \mathrm{~mm}$ distance, and $20 \mathrm{~g}$ auto-trigger [19]. Maximum shear force $(\mathrm{g})$ results are from three independent experiments, with three readings taken per experiment.

\section{Statistical analysis}

Descriptive statistics and Analysis of Variance (ANOVA) were performed using the descriptive statistics package of MS Excel (Microsoft Corp., Redmond, WA, USA). 
Citation: Sommers C, Mackay W, Geveke D, Lemmenes B, Pulsfus S (2012) Inactivation of Listeria innocua on Frankfurters by Flash Pasteurization and Lauric Arginate Ester. J Food Process Technol 3:147. doi:10.4172/2157-7110.1000147

Page 3 of 4

\section{Results and Discussion}

Flash pasteurization (FP) is a commercialized process that uses short pulses of steam to inactivate Listeria spp. on the surfaces of precooked sausages including frankfurters and bratwurst, and extend product shelf-life $[5,19]$. The technology can be used to decontaminate $50,000 \mathrm{~kg}$ of precooked sausages in modern meat processing plants per day. Like other post-process intervention technologies, FP is most effective when used in combination with antimicrobials which inhibit the growth of Listeria spp. during refrigerated storage $[7,18,19]$.

In this study the use of FP, when used in combination with the emerging GRAS antimicrobial lauric-arginate-ester (LAE), which is now widely used by the meat processing industry in the US, to inactivate $L$. innocua on frankfurter surfaces was investigated. $L$. innocua has been used as a surrogate microorganism in previous pilotplant scale studies for FP decontamination of frankfurters [5,7,17-19]. This is the first report on the efficacy of FP in combination with LAE as an antilisterial measure.

FP conditions $\left(1.5 \mathrm{~s}\right.$ steam, $\left.120^{\circ} \mathrm{C}\right)$ were used based on previous research and conditions of use in actual commercial practice, and resulted in 2-3 log reductions of $L$. monocytogenes and L. innocua [Personal Communication, Seth Pulsfus, Alkar-Rapid-Pak, Inc]. In this study FP reduced L. innocua levels by $2.5 \log$ CFU/g. In a previous study by Sommers et al. [6], a 5\% solution of LAE reduced populations of L. monocytogenes on frankfurter surfaces by $2.1 \mathrm{log} \mathrm{CFU} / \mathrm{g}$, and in this study $L$. innocua populations were reduced by $1.6 \log \mathrm{CFU} / \mathrm{g}$. Use of FP $\left(1.5 \mathrm{~s}, 120^{\circ} \mathrm{C}\right.$ steam) followed by application with LAE $(5 \%$ solution) resulted in a $3.1 \mathrm{log}$ reduction of L. innocua on frankfurter surfaces (Figure 1).

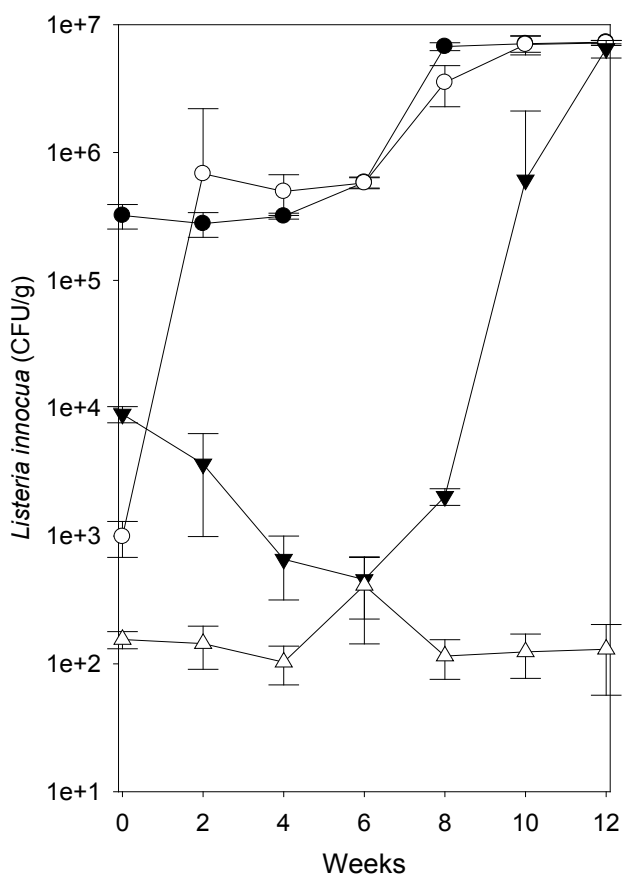

Figure 1: Growth of $L$. innocua on frankfurters $\left(10^{\circ} \mathrm{C}\right)$ treated with Flash Pasteurization and Lauric Arginate Ester. Untreated controls (closed circles); FP only (open circles); 5\% LAE only (closed triangles); and FP + LAE (open triangles) Standard error of the mean shown as error bars $(n=3)$.

\begin{tabular}{|c|c|c|c|c|c|}
\hline & Weeks & $\begin{array}{c}\text { Untreated } \\
\text { control }\end{array}$ & FP & LAE & FP+LAE \\
\hline a-value & 0 & $14.8( \pm 0.26) \mathrm{a}$ & $15.4( \pm 0.14) \mathrm{a}$ & $16.9( \pm 0.12) \mathrm{b}$ & $16.9( \pm 0.18) \mathrm{b}$ \\
\hline b-value & 0 & $26.7( \pm 0.51) \mathrm{a}$ & $27.7( \pm 0.34) \mathrm{a}$ & $29.5( \pm 0.23) \mathrm{b}$ & $29.9( \pm 0.42) \mathrm{b}$ \\
\hline L-value & 0 & $55.7( \pm 0.43) \mathrm{a}$ & $54.2( \pm 0.53) \mathrm{a}$ & $51.9( \pm 0.47) \mathrm{b}$ & $51.0( \pm 0.67) \mathrm{b}$ \\
\hline Shear & 0 & $1683( \pm 72.01) \mathrm{a}$ & $1993( \pm 376.4) \mathrm{a}$ & $1847( \pm 53.31) \mathrm{a}$ & $1898( \pm 48.97) \mathrm{a}$ \\
\hline a-value & 12 & $15.3( \pm 0.35) \mathrm{a}$ & $15.8( \pm 0.31) \mathrm{a}$ & $16.2( \pm 0.28) \mathrm{b}$ & $16.5( \pm 0.26) \mathrm{b}$ \\
\hline b-value & 12 & $27.2( \pm 0.62) \mathrm{a}$ & $27.0( \pm 0.59) \mathrm{a}$ & $29.8( \pm 0.33) \mathrm{b}$ & $29.5( \pm 0.23) \mathrm{b}$ \\
\hline L-value & 12 & $59.4( \pm 1.23) \mathrm{a}$ & $57.3( \pm 0.93) \mathrm{a}$ & $52.1( \pm 0.68) \mathrm{b}$ & $50.9( \pm 0.85) \mathrm{b}$ \\
\hline Shear & 12 & $1747( \pm 122.8) \mathrm{a}$ & $1841( \pm 242.5) \mathrm{a}$ & $1713( \pm 106.7) \mathrm{a}$ & $1802( \pm 113.4) \mathrm{a}$ \\
\hline
\end{tabular}

Each experiment was conducted independently 3 times $(n=3)$. Standard error of the mean is shown in parenthesis.

Different letters in rows indicate statistical difference as determined by ANOVA $(n=3, \alpha=0.05)$.

Table 1: Effect of Flash Pasteurization (FP) and Lauric Arginate Ester (LAE) on frankfurter color and shear force.

The effect of FP and LAE on growth of L. innocua during longterm refrigerated storage was also investigated. USDA-FSIS [21] recommends use of mild temperature abuse $\left(7-10^{\circ} \mathrm{C}\right)$ for evaluation of growth inhibitors and intervention technologies as part of post process lethality assessments. L. innocua inoculated onto untreated frankfurters, as noted in previous studies with Listeria spp., ultimately proliferated to $>10^{6} \mathrm{CFU} / \mathrm{g}$ during long-term storage. As expected, $L$. innocua treated using an intervention (FP) with no antimicrobial was able recover and proliferate during storage at $10^{\circ} \mathrm{C}$ (Figure 1) $[7,18]$. Application of LAE prevented proliferation of L. innocua for the first eight weeks of storage, however, the bacterium was able to recover and proliferate to $>10^{6} \mathrm{CFU} / \mathrm{g}$ by week 10 of storage at $10^{\circ} \mathrm{C}$ (Figure 1 ). This was in agreement with results obtained in other studies [6,22].

The most effective approach for control of Listeria was by application of both FP and LAE, with the bacterial growth being inhibited for the full 12 week storage period (Figure 1). We were unable to recover L. innocua on frankfurters treated with both FP and LAE when they were inoculated to a lower level of $10^{3} \mathrm{CFU} / \mathrm{g}$ which would be a more realistic post-process contamination level [10], but were able to recover L. innocua from frankfurters treated with FP or LAE alone, using the methods described in this study.

While FP and LAE are both used commercially, and have little effect on frankfurter quality attributes, assessments of frankfurter color and shear force were performed. FP had no effect on color of frankfurters. However, application of LAE resulted in increased redness (a-value) of $\mathrm{LAE}$ and $\mathrm{FP}+\mathrm{LAE}$ treated frankfurters, as well as b-value, which were maintained during 12 weeks of storage. As expected, FP + LAE had no effect on frankfurter shear force (Table 1).

Both processes, FP and application of LAE, have been commercialized. However, the use of FP in combination with LAE improved the inactivation of Listeria over that of the processes used individually. In conclusion, FP in combination with LAE is an effective hurdle process that can be used to control Listeria in pre-cooked sausages such as frankfurters.

\section{Acknowledgments}

We would like to thank Mr O Joseph Scullen and Ms. Kimberly Sokora for technical assistance. This research was conducted as part of a Cooperative Research and Development Agreement No. 58-3K95-7-1197-M between USDAARS and Alkar-RapidPak, Inc. We would like to thank A\&B Ingredients for the Lauric Arginate Ester. 
Citation: Sommers C, Mackay W, Geveke D, Lemmenes B, Pulsfus S (2012) Inactivation of Listeria innocua on Frankfurters by Flash Pasteurization and Lauric Arginate Ester. J Food Process Technol 3:147. doi:10.4172/2157-7110.1000147

\section{References}

1. Centers for Disease Control and Prevention (CDC) (2006) Preliminary FoodNet data on the incidence of infection with pathogens transmitted commonly through food -10 States, United States, 2005. MMWR Morb Mortal Wkly Rep 55: 392-395.

2. Centers for Disease Control and Prevention (CDC) (2008) Preliminary FoodNe data on the incidence of infection with pathogens transmitted commonly through food-10 States, 2007. MMWR Morb Mortal Wkly Rep 57: 366-370.

3. Denney J, McLauchlin J (2008) Human Listeria monocytogenes infections in Europe-an opportunity for improved European surveillance. Euro Surveill 13: 8082.

4. Mead PS, Slutsker L, Dietz V, McCaig LF, Bresee JS, et al. (1999) Food-related illness and death in the United States. Emerg Infect Dis 5: 607-625.

5. Sommers C, Geveke D (2006) Inactivation of Listeria on frankfurter surfaces using UVC radiation and vacuum-steam-vacuum pasteurization. In: McKeon T, Barton F, II, editors. Proceedings of the U.S.-Japan Cooperative Program in Natural Resources (UJNR) Protein Resources Panel, 35th Annual Meeting, October 21-28, 2006. pp. 23-25.

6. Sommers $\mathrm{CH}$, Scullen OJ, Sites JE (2010) Inactivation of foodborne pathogens on frankfurters using UV-C light and GRAS antimicrobials. J Food Saf 30: 666678

7. Murphy RY, Hanson RE, Johnson NR, Scott LL, Feze N, et al. (2005) Combining antimicrobials and steam treatment in a vacuum packaging system to contro Listeria monocytogenes on ready-to-eat frankfurters. J Food Sci 70: 135-140.

8. Murphy RY, Hanson RE, Feze N, Johnson NR, Scott LL, et al. (2005) Eradicating Listeria monocytogenes from fully cooked franks by using an integrated pasteurization-packaging system. J Food Prot 68: 507-511.

9. Chen Y, Ross WH, Scott VN, Gombas DE (2003) Listeria monocytogenes: low levels equals low risk. J Food Prot 66: 570-577.

10. Gerba CP, Rose JB, Haas CN (1996) Sensitive populations: who is at risk? Int J Food Microbiol 30: 113-123.

11. Sommers $\mathrm{CH}$, Thayer DW (2000) Survival of surface-inoculated Listeria monocytogenes on commercially available frankfurters following gamma irradiation. J Food Saf 20: 127-137.

12. Patel JR, Sanglay GC, Solomon MB (2009) Control of Listeria monocytogenes on frankfurters with antimicrobials and hydrodynamic pressure processing. $J$ Muscle Foods 20: 227-241.

13. Huang L, Sites J (2008) Elimination of Listeria monocytogenes on hotdogs by infrared surface treatment. J Food Sci 73: 27-31.

14. Huang L (2007) Computer simulation of heat transfer during in-package pasteurization of beef frankfurters by hot water immersion. J Food Eng 80: 839-849.

15. Knight TD, Castillo A, Maxim J, Keeton JT, Miller RK (2007) Effectiveness of potassium lactate and sodium diacetate in combination with irradiation to control Listeria monocytogenes on frankfurters. J Food Sci 72: 26-30.

16. Uesugi AR, Moraru Cl (2009) Reduction of Listeria on ready-to-eat sausages after exposure to a combination of pulsed light and nisin. J Food Prot 72: 347 353.
17. Kozempel M, Goldberg N, Scullen OJ, Radewonuk ER, Craig JC (2000) Rapid hot dog surface pasteurization using cycles of vacuum and steam to kill Listeria innocua. J Food Prot 63: 457-461.

18. Murphy RY, Hanson RE, Johnson NR, Chappa K, Berrang ME (2006) Combining organic acid treatment with steam pasteurization to eliminate Listeria monocytogenes on fully cooked frankfurters. J Food Prot 69: 47-52.

19. Sommers CH, Geveke DJ, Fan X (2008) Inactivation of Listeria innocua on frankfurters that contain potassium lactate and sodium diacetate by flash pasteurization. J Food Sci 73: 72-74.

20. Gombas DE, Chen Y, Clavero RS, Scott VN (2003) Survey of Listeria monocytogenes in ready-to-eat foods. J Food Prot 66: 559-569.

21. USDA FSIS (2006) Updated Compliance Guidelines. Compliance guidelines to control Listeria monocytogenes in post-lethality exposed ready-to-eat meat and poultry products

22. Porto-Fett ASC, Campano SG, Smith JL, Oser A, Call JE, et al. (2010) Contro of Listeria monocytogenes on commercially-produced frankfurters prepared with and without potassium lactate and sodium diacetate and surface treated with lauric arginate using the Sprayed Lethality in Container (SLIC ${ }^{\mathrm{TM}}$ ) delivery method. Meat Sci 85: 312-318.

23. Luchansky J, Call J, Smith J, Smith J, Oser A, et al. (2007) Viability of Listeria monocytogenes on commercially-prepared roast beef logs, turkey breast logs and frankfurters surface treated with lauric arginate and stored at 4 degree $\mathrm{C}$ for 24 hours. Meeting Abstract. International Association of Food Protections Annual Meeting. P2-24

24. Luchansky JB, Call JE, Hristova B, Rumery L, Yoder L, et al. (2005) Viability of Listeria monocytogenes on commercially-prepared hams surface treated with acidic calcium sulfate and lauric arginate and stored at $4^{\circ} \mathrm{C}$. Meat Sci 71: 92-99.

25. Scallan E, Hoekstra RM, Angulo FJ, Tauxe RV, Widdowson MA, et al. (2011) Foodborne illness acquired in the United States-major pathogens. Emerg Infect Dis 17: 7-12

26. Smith LT (1996) Role of osmolytes in adaptation of osmotically stressed and chill stressed Listeria monocytogenes grown in liquid media and on processed meat surfaces. Appl Environ Microbiol 62: 3088-3093.

27. U.S. FDA (2001) Relative risk to public health from foodborne Listeria monocytogenes among selected categories of ready-to-eat foods; Draft risk assessment document and risk management action plan; availability. Federa Register 66: 5515-5517.

28. U.S. FDA (2003) Quantitative assessment of the relative risk to public health from foodborne Listeria monocytogenes among selected categories of readyto-eat foods. U.S. Food and Drug Administration Center for Food Safety and Applied Nutrition, College Park, MD.

29. USDA FSIS (1989) Revised policy for controlling Listeria monocytogenes. Food Safety and Inspection Service, U.S. Dept. of Agriculture, Washington, DC. Federal Register 54: 22345-22346.

30. USDA FSIS (2011) FSIS recalls database. Available at: http://www.fsis.usda gov/fsis_recalls/Recall_Case_Archive_2011/index.asp. Accessed August 30, 2011. 